\title{
ODONTOMA COMPOSTO - RELATO DE CASO
}

Franciely ZANIN, Eduardo MORESCHI

Os odontomas são classificados como tumores odontogênicos mistos, são compostos de tecido de origem epitelial e mesenquimal, análogos da odontogênese que leva interpretá-los como hamartomas em vez de neoplasias. Sua origem é desconhecida, frequentemente encontra-se associados a dentes inclusos, germes dentários ou dentes supranumerários. São classificados em odontontomas complexo e compostos. A etiologia mais aceita relaciona-se a traumas, infecções ou pressão. Podem ser diagnosticados devido à anodontia, desvio da posição normal dos dentes ou em exames radiográficos de rotina, e quando detectado este deve ser removido cirurgicamente. Paciente gênero masculino, 20 anos, cor branca, compareceu à Clínica do Projeto de Lesões Bucais (PROLEB) do Centro Universitário de Maringá (CESUMAR) por encaminhamento do ortodontista, após detecção radiográfica de uma lesão assintomática, na região de incisivos superiores, do lado direito. Ao exame físico, observou-se irrompimento parcial dos dentes 11 e 12 e ausência de irrupção do dente 13. Ao exame radiográfico (periapical e oclusal), foi detectada área radiopaca, com halo radiolúcido, constituída por múltiplos dentículos. O tratamento proposto foi remoção cirúrgica. Doze dentículos foram obtidos e encaminhados para exame histopatológico. O diagnóstico final foi de Odontoma Composto. O prognóstico é favorável, a proservação radiográfica é importante para assegurar o sucesso do tratamento.

Palavras-chave: Odontoma composto; Hamartoma; Tumor odontogênico. 